\title{
Analysis of properties for Lime-metakaolin (L-MK) restoration mortar SONG Yan-Jun ${ }^{1}$, ZHANG Lu
}

1. School of Earth Science and Resources, Chang'an University, Xi'an, 710000, China

2. Institute of Prospecting Technology, Hebei mine bureau, Langfang, 065000, China

Kew words: L-MK; repairing mortar; auxiliary material; drying

\begin{abstract}
There are various factors affecting drying shrinkage of cement-based material, including use quantity of cement and auxiliary cementitious material, water cement ratio, maintenance system and drying condition, and in addition, total quantity of coarse and fine aggregate, matching and category also affect drying shrinkage of cement-based material. But seen from composition and structure of mortar, shrinkage distortion is mainly caused by shrinkage of multi-pore binder phase, i.e. C-S-H gel phase. Evaporation and migration of evaporable water in pore are main source of drying shrinkage power. On the other hand, drying shrinkage performance of mortar is closely concerned with composition and structure of mortar (maturity of mortar) when drying starts. Pozzolanic reaction of auxiliary cementitious material in mortar occurs after certain age of mortar hydration to maintain mortar of different ages (i.e. mortar of different maturity), and essential difference shall exist in its drying shrinkage distortion mechanism. To clearly describe drying shrinkage mechanism where MK affects cement-based material, this paper researches drying shrinkage and weightlessness behavior of cement mortar of different maturity and with different MK content under 55 $\pm 5 \%$ R.H. condition, and researches composition and pore structure of mortar of different maturity by adopting thermal synthetic analysis (TG/DSC) and mercury intrusion method (MIP).
\end{abstract}

\section{Introduction}

Drying shrinkage is one of the most popular and important factors affecting volume stability and project application of cement-based material. As indispensable component to prepare high-performance cement-based material, various auxiliary cementitious materials have important effect on drying shrinkage performance of cement-based material. Composition complexity and active difference exist in industrial by-product, such as coal ash, slag and silica fume etc. because of effect of source and handling process, difference of performance and effect[1-3] often appears for their application in cement-based material.

Recently, more and more importance[4, 5] has been attached to application of metakaolin (MK) as artificial pozzolanic materials gained from normative production process to high-performance cement-based material. Researches have shown that pozzolanic activity of MK is much greater than that of slag and coal ash, closer to that of silica fume, and MK can improve strength and penetration resistance of cement-based material significantly, and restrains alkali-aggregate reaction and chemical attack. Few researches show [9-14] that MK can reduce shrinkage distortion of cement-based material, and shrinkage distortion reduction effect of MK outweighs coal ash, slag and silica fume. Because of difference of test condition (MK quality, specimen composition, maturity and drying condition etc.) adoption by different researchers, as for opinion on cement-based material shrinkage reduction mechanism of $\mathrm{MK}$, although attention is mainly paid to micro-aggregate effect and pozzolanic effect of MK, uniform cognition does not exist.

\section{Raw material and test method}

\subsection{Raw material}

Jiangnan Onoda PII52.5 ordinary portland cement includes 5\% limestone. Average grain diameter of superfine metakaolin (MK) sold on market is about $1 \mu \mathrm{m}$. See table 1 for chemical 
composition of cement and MK. According to chemical composition, content of various mineral phases of cement is respectively calculated as: C3S $46.7 \%$, C2S $25.9 \%$, C3A $6.8 \%$ and C4AF $10.0 \%$. Analysis of X-ray diffraction (XRD) shows that MK includes a good deal of amorphous $\mathrm{SiO} 2, \mathrm{Al} 2 \mathrm{O} 3$ and few quartz and mullite crystal.

\subsection{Test method}

Drying shrinkage and weightlessness: to eliminate effect of aggregate on shrinkage, neat mortar specimen is adopted. Refer to standard JCT 603-2004 Standard Test Method for Drying Shrinkage of Mortar for preparation, maintenance and measurement of specimen in test. MK replaces $0 \%, 5 \%$, $10 \%$ and $15 \%$ cement respectively with 0.33 water cement ratio (w/c).

Table1. Chemical composition of cement and metakaolin/ wt\%

Materials $\mathrm{LOI} \mathrm{SO}_{3} \mathrm{SiO}_{2} \mathrm{Fe}_{2} \mathrm{O}_{3} \mathrm{Al}_{2} \mathrm{O}_{3} \mathrm{CaO} \quad \mathrm{MgO} \mathrm{K}_{2} \mathrm{O} \mathrm{Na} \mathrm{Na} \mathrm{TiO}_{2}$

\begin{tabular}{ccccccccccc}
\hline MK & - & - & 55.03 & 0.82 & 43.33 & - & - & 0.46 & - & 0.34 \\
Cement & 2.92 & 2.55 & 21.2 & 3.30 & 4.65 & 62.59 & 1.13 & 0.68 & 0.06 & 0.21
\end{tabular}

Pour into $20 \mathrm{~mm} \times 20 \mathrm{~mm} \times 80 \mathrm{~mm}$ quadruple-mould mould with pin fin for molding after stirring with water. Perform demoulding after it is maintained at $20^{\circ} \mathrm{C}$ thermostatic chamber where relative humidity is great than $95 \% \mathrm{RH}$ for $24 \mathrm{~h}$. Specimen is transferred to $20^{\circ} \mathrm{C}$ water and has been respectively maintained for $3 \mathrm{~d}$ and $28 \mathrm{~d}$ after demoulding. After it reaches to specified age through maintenance, take out specimen and wipe water on surface. Measure relative initial length 10 of specimen promptly with comparator and weigh weight W0. Transfer specimen into $20 \pm 5^{\circ} \mathrm{C}$ and $55 \pm 5 \%$ RH drying oven with constant temperature and humidity immediately after measurement. Certain gap shall be kept and place in order for drying. After it reaches to certain age through drying, take it out and measure relative length lt and weight Wt immediately and place mortar into drying oven for continuous drying.

When it has been dried for $\mathrm{t}$ days, drying shrinkage St $(\mu \mathrm{m} / \mathrm{m})$ of specimen is calculated according to following formula:

$$
S_{t}=\frac{L_{0}-L_{t}}{80-2 \Delta l} \times 10^{6}
$$

$\triangle$ l-sticking depth of pin fin on both ends of specimen, supposed as $2.5 \mathrm{~mm}$.

Correspondingly, drying quality loss rate wt of specimen is calculated according to following formula:

$$
w_{t}=\frac{W_{0}-W_{t}}{W_{0}} \times 100 \%
$$

Pore structure and thermal synthetic analysis of mortar: take mortar of different matching after maintenance for 3d and 28d, cut and soak for 4d with absolute ethyl alcohol to stop its hydration. Dry for $3 \mathrm{~d}$ under vacuum after that (vacuum degree -0.1MPa, indoor temperature). A part of sample is broken, grinded and sieved. Take $3 g$ sample of which grain diameter is $16 \mathrm{mu} 32 \mathrm{mu}$, measure pore structure of mortar with Poromaster GT-60 mercury injection apparatus and main test parameter is: contact angle of mercury is determined as $140^{\circ}$, surface tension is $480 \mathrm{erg} / \mathrm{cm} 3$, density is $13.5 \mathrm{~g} / \mathrm{cm} 3$, and pressure range is $0-200 \mathrm{MPa}$. Take sample sieved through $200 \mathrm{mu}$, adopt STA449C thermal synthetic analyzer of NETZSCH Company to perform TG/DSC test, and test condition is: normal temperature increase to $900^{\circ} \mathrm{C}$ with $10^{\circ} \mathrm{C} / \mathrm{min}$ temperature increase rate.

\section{Property analysis on repairing mortar}

\subsection{Effect of mortar maturity on drying shrinkage}

Fig. 1 and Fig.2 are respectively drying shrinkage curves of complex MK cement mortars that have been maintained for $3 \mathrm{~d}$ and $28 \mathrm{~d}$ in $20^{\circ} \mathrm{C}$ water and that have been dried for $90 \mathrm{~d}$ under condition of $20^{\circ} \mathrm{C}$ and $55 \% \mathrm{RH}$.

Seen from Fig.1, drying shrinkage of all mortars that have been maintained in water for 3d 
increases rapidly at earlier stage $(<14 \mathrm{~d})$ with increase of drying time. Drying shrinkage of mortar including $\mathrm{MK}$ is slightly greater than reference, and there is no obvious shrinkage difference for mortar with different MK adulterate amount. After drying for 21d, drying shrinkage increase of all mortars slows down, and shrinkage value of mortar including MK is lower than that of mortar of net mortar (P0), and the greater the content of MK is, the smaller drying shrinkage of mortar will be. Compared with P0, drying shrinkage of mortar where 5\%, $10 \%$ and $15 \% \mathrm{MK}$ are adulterated reduces by $5 \%, 16 \%$ and $22 \%$ respectively after drying for 90 days.

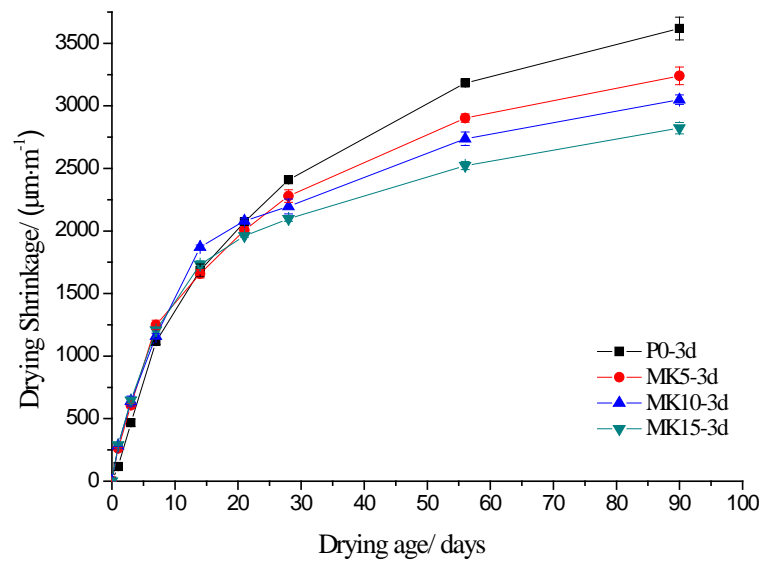

Fig.1 Drying Shrinkage Curve of Various Mortars after Pre-maintenance for 3d (20 ${ }^{\circ} \mathrm{C}, 55 \%$ R.H.)

Similar to mortar after pre-maintenance for 3d, rapid increase at earlier stage, increase slowing and stability tendency etc. (Fig.2) also exist in drying shrinkage of mortar after pre-maintenance for $28 \mathrm{~d}$ in water. What is different is that for pre-maintenance for 28d in water, drying shrinkage of complex MK cement mortar is lower than that of $\mathrm{P} 0$ within all ages researched, and the greater the content of MK is, the smaller shrinkage of mortar will be. But drying shrinkage of complex MK cement mortar shows rapid increase at previous $14 \mathrm{~d}$, increase slowing between $14 \mathrm{~d} \sim 28 \mathrm{~d}$ and increase with relatively rate after $28 \mathrm{~d}$ and stability tendency at last. Compared with P0, drying shrinkage of mortar where 5\%, 10\% and 15\% MK are adulterated reduces by $7 \%, 19 \%$ and $32 \%$ respectively after drying for 90 days.

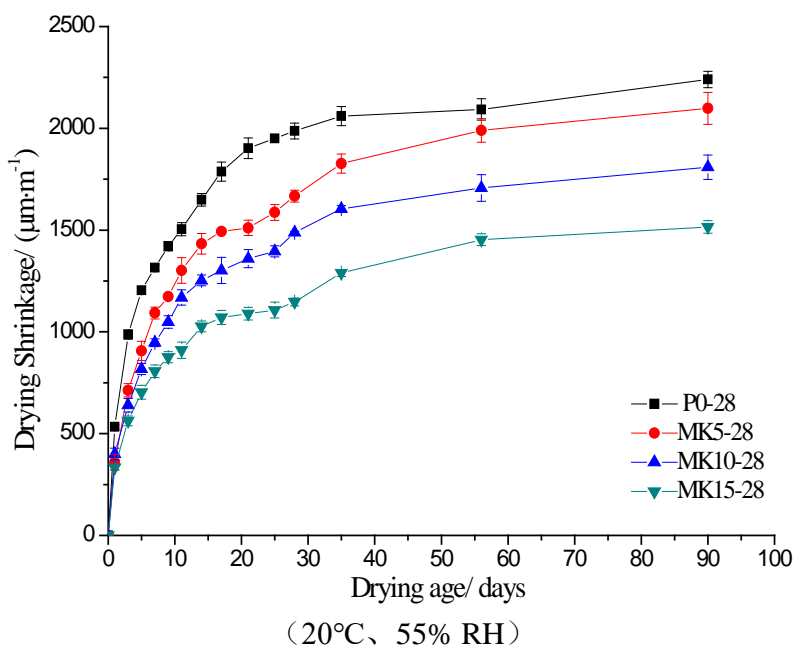

Fig.2 Drying Shrinkage Curve of Various Mortars after Pre-maintenance for $28 \mathrm{~d}\left(20^{\circ} \mathrm{C}, 55 \% \mathrm{RH}\right)$

It can be concluded that pre-maintenance age of mortar before drying (maturity of mortar) has obvious effect on its drying shrinkage behavior after comparison of Fig.1 and Fig.2. When drying time is the same, drying shrinkage value of mortar after pre-maintenance for $3 \mathrm{~d}$ is much greater than that of mortar after pre-maintenance for 28d. Obvious difference exists in drying shrinkage development law of mortar of which maturity is 3d and 28d with MK. Drying shrinkage of mortar after pre-maintenance for 3d increases continuously with increase of age but increase rate reduces continuously; drying shrinkage of mortar after pre-maintenance for 28d represents multistep 
development, which shows that influence or effect of MK on drying shrinkage is different significantly in mortar of different maturity, and sufficient pre-maintenance helps to give play to drying shrinkage reduction effect of MK to cement-based material.

\section{Conclusion}

Effect of MK on shrinkage of cement mortar is significant, and its effect degree is closely concerned with MK adulterate amount and maturity of mortar. MK can reduce long-term drying shrinkage of mortar, and within certain adulterate amount range, the higher the adulterate amount of MK is, the smaller the drying shrinkage of mortar will be. Effect of MK on early-age drying shrinkage mainly depends on maturity of mortar. MK can reduce shrinkage of high-maturity mortar, but it does not have significant effect on drying shrinkage of low-maturity mortar and even with slight increase. Good linear dependence exists between drying shrinkage of mortar with different MK contents and weightlessness within certain range. Internal water loss mechanism of mortar at different stages and shrinkage degree caused by it are different. In mortar of different maturity, mechanism of MK affecting its drying shrinkage is different. mortar after pre-maintenance for 3d is mainly coefficient result of MK crystal nucleus effect, micro-aggregate effect, pozzolanic effect at early stage of drying, and continuous hydration of mortar, but as for mortar after pre-maintenance for 28d, various physical and chemical effects of MK have been finished basically, and drying shrinkage distortion of mortar is mainly controlled by water loss of small pore of mortar and gel pore.

\section{References}

[1] Munakata Y, Kasai S. Modification effects of colloidal nanoSiO2 on cement hydration and its gel property[J]. Composites Part B Engineering, 2013, 45(1):440-448.

[2] Silva R V, Brito J D, Dhir R K. Properties and composition of recycled aggregates from construction and demolition waste suitable for concrete production[J]. Construction \& Building Materials, 2014, 65(13):201-217.

[3] Schiffner T, Sattentau Q J, Dorrell L. Development of prophylactic vaccines against HIV-1[M]// U.S. capitalist development since 1776 :. M.E. Sharpe, 2013:1-16.

[4] Kylili A, Fokaides P A, Christou P, et al. Infrared thermography (IRT) applications for building diagnostics: A review[J]. Applied Energy, 2014, 134:531-549.

[5] Pacheco-Torgal F. Eco-efficient construction and building materials research under the EU Framework Programme Horizon 2020[J]. Construction \& Building Materials, 2014, 51:151-162. 